\title{
O processo de formação política da Marcha Mundial das Mulheres - Núcleo Agreste de Pernambuco
}

\begin{abstract}
Resumo: O presente artigo é um estudo sobre a formação política desenvolvida na Marcha Mundial das Mulheres - Núcleo Agreste de Pernambuco. Temos como objetivo geral compreender como se dá o processo de formação política da Marcha Mundial das Mulheres diante de uma sociedade patriarcal, juntamente com os objetivos específicos: identificar o processo de formação política da Marcha Mundial das Mulheres; caracterizar este movimento e descrever as principais condições de opressão sexista em que as mulheres vivem no patriarcalismo. Este trabalho justifica-se pela emergência de uma prática feminista dentro dos movimentos sociais, como é o caso da Marcha Mundial das Mulheres- Núcleo Agreste. Nossa problematização é saber como ocorre o processo de formação política dessa marcha diante de uma sociedade patriarcal? Em nossa metodologia adotamos uma pesquisa qualitativa/ exploratória/ explicativa e descritiva, apoiada ao estudo do Caso Alargado para análise e sistematização dos dados, também utilizamos as bases teóricas apoiadas pelas epistemologias feministas e teorias de gênero para situar o nosso trabalho dentro de um contexto atual. Nossas conclusões foram na linha horizontal e não linear de construir o conhecimento sobre os enfrentamentos oriundos do patriarcado e do sexismo, construindo uma epistemologia feminista de prática não sexista.
\end{abstract}

Palavras-chave: Feminismo. Formação Política. Gênero. Patriarcado.

\section{Introdução}

Diante do almejo de construirmos uma sociedade mais igualitária, livre do preconceito, em que homens e mulheres sejam tratados e respeitados da mesma forma, é necessário identificar e compreender as dificuldades que nós mulheres temos tido para promover reivindicações e lutas em nossa defesa, com isso problematizar, subverter e desestabilizar a sociedade patriarcal. Do mesmo modo que nós estudantes e profissionais da educação, precisamos ter uma consciência crítica que estamos numa sociedade machista, que nos envolve em situações para que continuemos a reproduzir e perpetuar o machismo, o sexismo, a homofobia, o preconceito, o racismo e o capitalismo.

Em contrapartida, os movimentos sociais vão pensar em valores e crenças, para ações coletivas que objetivam alcançar mudanças sociais através do embate político por meio de suas ideologias. No atual cenário político do país, com o impeachment da primeira mu1her presidenta do Brasil, onde se registra uma forte transformação,
Érika Patrícia Barbosa de Lima Universidade Federal de Pernambuco (UFPE) erikap.lima23@outlook.com Allene Carvalho Lage Universidade Federal de Pernambuco (UFPE) allenelage@yahoo.com.br Filipe Antonio Ferreira da Silva Universidade Federal de Pernambuco (UFPE) filipe.antonio20@hotmail.com 
podemos observar o preconceito com as mulheres no poder. Temos um governo que não tem mulheres em seus ministérios e que promove ações para conservar o autoritarismo dos homens em relação às mulheres e ao poder. O movimento feminista tem se fortalecido e aumentado sua visibilidade, em manifestos para a conscientização do papel da mulher na sociedade e no poder, as pautas utilizadas mostram, principalmente, a formação política dessas mulheres para as conquistas dos seus direitos.

A perspectiva educativa no movimento feminista será outro ponto crucial do nosso estudo, pois mostrará o trabalho de ativistas nas mais variadas ações de reivindicações contra a sociedade patriarcal, ora nos âmbitos das universidades e faculdades, ora nas ruas ou em organizações. O movimento feminista abordado no presente estudo será a Marcha Mundial das Mulheres (MMM) que têm diversas conquistas alcançadas no Brasil e no mundo, como o direito a creche, o aumento do salário mínimo, as delegacias das mulheres - tanto as móveis na região norte e como as sedes fixas - , economia solidária, entre outras ações nas quais MMM se agrupa com outros movimentos feministas. E muitas pautas que ainda continuam com muitas reivindicações e tendo retrocessos diante do atual cenário político, como é o caso da legalização do aborto; o combate a lesbofobia, bifobia e feminicídio; a entrada de mais mulheres nos poderes Executivo, Legislativo e Judiciário.

Diante dessa conjuntura este artigo pretende expandir reflexões para a seguinte pergunta: Como ocorre o processo de formação política da Marcha Mundial das Mulheres - Núcleo Agreste diante de uma sociedade patriarcal?

Com o problema apresentado, pretendemos refletir sobre o processo de formação política das mulheres, a partir da Marcha Mundial das Mulheres - Núcleo Agreste (MMM - NA) diante da sociedade patriarcal e machista que vivemos, na qual a mulher é tratada e vista como um ser inferior aos homens e aos quais devem respeito e obediência; como reverter esse quadro de relação de poder e opressão para uma sociedade igualitária, buscando fazer dessas formações espaços para o fortalecimento das mulheres, para a tomada de consciência da importância da atuação da mulher na sociedade e para a construção de pautas de lutas e reivindicações.

O principal objetivo desse artigo é compreender como se dá o processo de formação política da MMM diante de uma sociedade patriarcal. Entre os objetivos específicos, podemos destacar os 
seguintes: a) caracterizar o Movimento da Marcha Mundial das Mulheres enquanto espaço de formação; b) identificar o processo de formação política dessa marcha e c) descrever as principais condições de opressão sexista em que as mulheres vivem no patriarcalismo.

\section{A emergência do feminismo}

Ao longo do processo histórico sempre existiram mulheres que não aceitavam de forma pacífica a condição na qual eram the impostas, mulheres que sempre se rebelaram por lutarem por sua liberdade, e sempre foram negadas e silenciadas em sua contribuição histórica por uma ideologia patriarcal e machista. Para iniciarmos a compreensão sobre o feminismo, compreendemos seu conceito a partir das afirmações de Teles (1993, p. 10):

O feminismo é um movimento político. Questiona as relações de poder, a opressão e exploração de grupos de pessoas sobre as outras. Contrapõe-se radicalmente ao poder patriarcal. Propõe uma transformação social, econômica, política e ideológica da sociedade.

Nesse sentindo, entendemos que o feminismo está ligado ao conceito de libertação, pois as mulheres têm sido vítimas do imaginário patriarcal que as colocam como inferiores ao poder, a força e a inteligência do homem, mostrando que existe uma opressão contra as mulheres, e essa libertação vai se caracterizando por sua emancipação e empoderamento, na busca de igualdade de direitos.

As/os pesquisadoras/es costumam dividir o movimento feminista em três fases denominadas "ondas feministas". A primeira onda do feminismo, foi no século XIX e meados do século XX, internacionalmente foi identificada como sufragista, que foi desenvolvido principalmente nos países de capitalismo avançado, como Estados Unidos e na Inglaterra, na qual as mulheres saíam às ruas e exigindo maior participação no mundo político, e o principal anseio das militantes foi o direito ao voto e garantias de igualdade de direitos entre os sexos. Essa onda se estendeu a outros países como o Brasil, onde a onda sufragista é caracterizada por traços de um feminismo burguês, branco e heterossexual, direcionados para mulheres das camadas sociais alta e média sociedade brasileira, que tiveram oportunidade de estudar em outros países. 
(1) Foi uma assistente social, advogada e ativista de direitos humanos brasileira, fundadora e líder do movimento feminino pela anistia.

A segunda onda do feminismo teve início na década de 1960 e continuou até o final de 1980, ficou marcada com o livro de Simone de Beauvoir: O segundo sexo (1949). No Brasil, a segunda onda viveu fortes movimentações no campo das lutas das mulheres, mas em 1964 com o golpe da Ditadura Militar, a forte repressão do regime ditatorial tentou silenciar mais uma vez as mulheres. Ao decorrer das grandes manifestações feministas pelo país pelo fim da Ditadura, a Organização das Nações Unidas (ONU) decretou em 1975 o ano Internacional da Mulher. As comemorações dessa data foram realizadas no Rio de Janeiro com o tema: "O papel e comportamento da mulher na realidade brasileira". Nesse ano as mulheres feministas lutavam também pela anistia das mulheres que foram expulsas do Brasil. Ao regressarem ao país, essas mulheres traziam uma bagagem de cultura e política nas formas de pensar e desestabilizar os padrões impostos pela sociedade brasileira. Como bem comenta Pinto (2003, p. 67):

\begin{abstract}
A anistia trouxe de volta ao Brasil um conjunto significante de militantes que haviam sido a vanguarda da esquerda brasileira nos anos de 1960. Pessoas que viveram por muitos anos no exterior, principalmente na Europa, voltavam com novas idéias e muitas vezes chocavam aqueles que haviam crescido no Brasil da década de 1970 e idealizavam os líderes exilados. Mas a anistia também marcou o início de uma época de maior liberalização, menos repressão, menos medo e mais possibilidades de manifestação.
\end{abstract}

Nesse momento, as feministas alcançam grande repercussão por todo o país, onde diferentes conjunturas eram organizadas na luta pelo direito das mulheres e sua principal articuladora foi Therezinha Zerbini ${ }^{1}$. As mulheres feministas começam a introduzir os estudos da mulher nos vários campos do conhecimento, trazendo ao debate características universalizantes femininas, denunciando sua invisibilidade e criando grupos para reescrever a história e "novas vozes começaram a ecoar dentro do restrito campo científico, reivindicando pluralidade assumindo uma luta - protagonizada por intelectuais feministas - para denunciar uma tradição científica sexista". (LAGE, 2008, p. 202) As pesquisadoras feministas denunciavam a neutralidade da ciência, assumindo uma subversão ao escrever e a interpelar os discursos machistas. 
A terceira onda veio na década de 1990 e continua até nossos dias atuais, que é marcada pelas pluralidades femininas, onde dentro do movimento feminista há outros subgrupos que ganham destaque como é o caso das mulheres negras, lésbicas, bissexuais, transexuais e trabalhadoras rurais. Algumas pesquisadoras denominam esse momento como pós-feminismo. De acordo com Macedo (2006, p. 814) esse termo se explica como:

De pós-feminismo poderá assim traduzir a existência hoje de uma multiplicidade de feminismos, ou de um feminismo 'plural', que reconhece o factor da diferença como uma recusa da hegemonia de um tipo de feminismo sobre outro, sem, contudo, pretender fazer tabula rasa das batalhas ganhas, nem reificar ou 'fetichizar' o próprio conceito de diferença.

Nessa situação, cada grupo de mulheres luta diante das suas principais necessidades, reconhecendo as diferenças da diversidade de mulheres que são envolvidas no movimento feminista, sem que um grupo se sobressaia ao outro, mas que no coletivo todas as mulheres consigam a igualdade entre homens e mulheres.

Para a autora Heloisa Buarque de Hollanda (2012, p. 12), nós estamos vivenciando a quarta onda do feminismo, que apresenta:

A existência de uma nova geração política, na qual se incluem as feministas, com estratégias próprias, criando formas de organização desconhecidas para mim, autônomas, desprezando a mediação representativa, horizontal, sem lideranças e protagonismos, baseadas em narrativas de si, de experiências pessoais que ecoam coletivas, valorizando mais a ética do que a ideologia, mais insurgência do que a revolução. Enfim, outra geração.

Dessa forma, tais perspectivas do movimento feminista surgem em um cenário político bastante polarizado, e a internet como campo aberto de subjetividades é hoje um caminho consolidado de busca de informações e de formação política. Pensar também outros corpos que habitam o devir feminista é uma conquista e uma tensão, pois tais corpos e performances divergem, ora na transição do corpo trans, do corpo lésbico, do corpo negro, que desestabilizam os papéis binários da sociedade e afrontam a ideologia heterossexista. 


\section{Formação política}

A divisão de classes sociais sempre ocorreu no Brasil e no mundo, com a chegada do capitalismo a desigualdade social cresceu mundialmente, a população que vinha lutando por direitos não firmados, compreendeu que a partir da união entre as/os sujeitas/ os subalternizadas/os na luta organizada poderiam reivindicar um novo modelo de sociedade anticapitalista. Como contextualiza Maria Militão (2014, p. 619):

Em qualquer contexto dado, a organização das classes subalternas é uma exigência fundamental, pois é na luta organizada que os segmentos sociais subalternos podem elevar sua consciência e sua solidariedade e se constituírem em sujeitos coletivos.

Quando nos deparamos com um grupo ou vários grupos de pessoas que comunguem do mesmo pensamento, da mesma luta de classes, a troca de experiências nos mostra o quanto somos colocados à margem e silenciados por uma sociedade capitalista. Quando tomamos a consciência que somos seres capazes de reivindicar nossos direitos notamos o quão se faz importante o coletivo junto, criar uma bandeira de luta, estar preparado e com ações organizadas para desestabilizar a classe dominante. Pois entendemos que "[...] é na coletividade que se elabora uma identidade e se organizam práticas por meios das quais os sujeitos expressam e defendem seus interesses e vontades". (MILITÃO, 2014, p. 619)

Diante das lutas travadas por esse coletivo, percebe-se que ter o conhecimento empírico de outras/os subalternizadas/os não se conquistaria espaços nos quais a classe dominante deliberaria negociações para tentar resolver esses conflitos. Descobre-se, então, o quão necessário é sair do empírico, para buscar outras possibilidades de participação política com uma nova demanda até então diferenciada dos movimentos sociais na qual é exigida a formação política qualificada dos participantes acerca da atuação desse coletivo na luta por direitos. Na Constituição Federal de 1988, as institucionalizações dos espaços de participação política foram reconhecidas, como Cileda Perella (2012, p. 64) nos afirma que:

Não basta a criação desses espaços, é preciso qualificar as pessoas para a sua devida ocupação, enfim, para que se constitua como espaço democrático, caso contrário, o que pode se ter é a criação de espaços em que a pseudodemocracia se instala, uma 
vez que podem servir à manipulação, à manutenção de ações comprometidas com o sistema opressor e dominante.

Com isso, a pesquisadora nos apresenta o quanto é importante essa formação política no sentido de que as pessoas se qualificando criem espaços de democracia, que compreendam o sistema de opressão e da classe dominante, para que não sejam manipulados e com isso deixem de lutar por seus ideais de ações sociais coletivas e estejam prontos para participar de confrontos e negociações entre o sistema opressor e os oprimidos. Para compreendermos a formação política nos movimentos sociais é necessário entender que os movimentos abrangem diferentes e diversificados tipos de ações, em síntese a pesquisadora Maria da Glória Gohn (2011, p. 335) nos explica que os movimentos sociais se pautam com:

Ações sociais coletivas, de caráter sociopolítico e cultural, que viabilizam distintas formas de organização e de expressão das demandas da população. Na ação concreta, essas formas adotam diferentes pressões diretas (mobilizações, marchas, concentrações, distúrbios de ordem constituída, atos de desobediência civil, negociações, etc.) até as pressões indiretas.

No contexto de luta e resistência, os movimentos sociais precisam de mobilizações que ocorram antes com seus sujeitos que participam (análise de conjuntura), para que percebam seu papel diante das ações que irão realizar. Como uma tomada de consciência, a compreensão de sua ideologia, o respaldo político que envolve a sua ação, pois para adotar as mais diferentes pressões se faz necessário processos educativos de formação com o povo.

\section{Patriarcado}

Nos estudos feministas, o termo patriarcalismo foi frequentemente utilizado para explicar a dominação masculina frente à condição feminina na sociedade, nos quais o termo patriarcado é um conceito que deve ser utilizado de forma abrangente, abarcando todos os níveis da organização social, não apenas a família. Como nos afirma as autoras Mirela Morgante e Maria Beatriz Nader (2014, p. 3) sobre o conceito de patriarcado enquanto:

Um sistema de dominação dos homens sobre as mulheres permite visualizar que a dominação não está presente somente 
na esfera familiar, tampouco apenas no âmbito trabalhista, ou na mídia ou na política. O patriarcalismo compõe a dinâmica social como um todo, estando inclusive, inculcado no inconsciente de homens e mulheres individualmente e no coletivo enquanto categorias sociais.

Nesse contexto a autoridade imposta pelos homens sobre as mulheres e filhos/as permeia toda a organização da sociedade, da produção e do consumo, da política, da religião, da legislação e cultura, na qual é arraigada e perpetuada de geração em geração. Até que os movimentos feministas reivindicam a não aceitação do que lhes são impostos pela sociedade, transformam e desestabilizam o pensamento pós-patriarcalista, lutando para quebrar esses paradigmas que vêm desde as sociedades tradicionais e que até hoje ainda são perpetuados. Segundo Neuma Aguiar (1997, p. 177-178):

O patriarcado deixa de ser uma dimensão das sociedades tradicionais e passa ser uma característica das sociedades modernas, ou do processo de modernização, observado como um capitalismo patriarcal ou um patriarcalismo do Estado-debem-estar-social. [...] A exclusão das mulheres das possibilidades de contratação e os contratos salariais diferenciados para homens e mulheres são exemplos desse particularismo.

O modelo patriarcal nos impregnou durante vários séculos o ideário feminino, nos inferiorizando e o tempo todo utilizando de vários mecanismos para constituir no subconsciente que somos seres a mercê do ideário machista, e estes mecanismos estão fortemente arraigados em mulheres e homens. As discriminações que sentimos por sermos mulheres e as práticas sexistas reforçam que somos seres sem importância socialmente. Para compreendermos o que é o sexismo e como ele impregna a sociedade, Karin Smigay (2002, p. 34) nos destaca:

Sexismo é a atitude de discriminação em relação às mulheres. Mas é importante lembrar que se trata de uma posição, que pode ser perpetrada tanto por homens quanto por mulheres, portanto, o sexismo está presente intragêneros tanto quanto entre gêneros. Inscrita numa cultura falocrática, impregna o imaginário social e o prepara a um vasto conjunto de representações socialmente partilhadas de opiniões e de tendências a práticas que desprezam, desqualificam, desautorizam e violentam as mulheres, tomadas como seres de menor prestígio social. 
O patriarcado utiliza de violências sexistas para continuar suas práticas que discriminam e inferiorizam as mulheres, tanto por homens como pelas próprias mulheres. Onde desde pequenas as meninas são ensinadas que devem obedecer à figura do pai e consequentemente o marido - que as mulheres devem cozinhar, cuidar dos filhos, serem boas domésticas, que as mesmas não têm direitos, que existem brinquedos e brincadeiras de homens e mu1heres, que tem profissões que são feitas para mulheres e homens, fazendo com que cada vez mais as práticas sexistas perpetuam o lugar de homens e mulheres na sociedade. Para sintetizar a construção do feminino subalternizado Marilena Chauí (1995) citada por Karin Smigay (2002, p. 36) nos ressalta que:

As argumentações acerca da construção do feminino, nesse modelo, tomavam a mulher como submetida/passiva/vítima, ainda que produzindo ações violentas: a relação com o outro se estabelecendo sempre em condições de desigualdade. Ela não seria sujeito constituinte de seu destino.

Essa construção sobre as mulheres a partir de uma perspectiva do patriarcado, na qual a mulher é um ser inferior, passivo e submisso, que sofre violências físicas e psicológicas que perpassam por ambientes que deveriam ser de pertencimento como a esfera da família e continuam a ser perpetuados na sociedade civil e no Estado, mostram que as relações patriarcais são de um domínio totalizante sobre a vida das mulheres. E essa dominação abarca os vários tipos de mulheres que dentro desse sistema totalizante de dominação masculina são silenciadas e subalternizadas. Como nos fala uma das maiores teóricas do Brasil em discussões de gênero e patriarcado, Heleieth Saffioti (2004, p. 54):

As relações de patriarcais, suas hierarquias, sua estrutura de poder contaminam toda a sociedade, o direito patriarcal perpassa não apenas a sociedade civil, mas impregna também o Estado. Ainda que não se possa negar o domínio de atividades públicas no espaço do trabalho, do Estado, do lazer coletivo, e, portanto, as diferenças entre o público e o privado, estão estes espaços profundamente ligados e parcialmente mesclados. Para fins analíticos, trata-se de esferas distintas; são, contudo, inseparáveis para a compreensão do todo social. 
Como podemos perceber na fala de Saffioti (2004), o patriarcado está intrinsecamente ligado ao pensamento social e também ao Estado, no qual a concepção de política hegemônica silencia a luta das mulheres para evadir este sistema dicotômico. A fuga dessa dicotomia se dá pela luta da emancipação feminina.

\title{
Metodologia
}

Almejando o enriquecimento do nosso aprendizado a partir das experiências, optamos por uma pesquisa de cunho qualitativo, pois acreditamos que este tipo de pesquisa abrange uma abordagem social sem desvincular a teoria com a realidade, buscando produzir informações aprofundadas. Para ampliar o conhecimento sobre as questões centrais da pesquisa qualitativa, trazemos as contribuições de Lage (2013, p. 50):

\begin{abstract}
A pesquisa qualitativa tem um viés que leva o investigador ao encontro de subjetividades que não conseguem se esconder, como acontece no universo da pesquisa quantitativa. As subjetividades afloram das regras e condicionamentos prévios, no contato, no diálogo e no confronto da realidade. Entender estas subjetividades e delas extrair novas compreensões requer metodologias claras, que possam admitir a diversidade de discursos, sentidos.
\end{abstract}

Quando abordamos em uma pesquisa questões que envolvem sentimentos, opiniões, colocações dos sujeitos, estas não podem ser classificadas ou quantificadas; pois a pesquisa qualitativa se preocupa com a interpretação e a compreensão dos fenômenos a partir de reflexões e inferências. Desta forma Minayo (2008, p. 21) diz que:

Esse conjunto de fenômenos humanos é entendido aqui como parte da realidade social, pois o ser humano se distingue não só por agir, mas por pensar sobre o que faz e por interpretar suas ações dentro e a partir da realidade vivida e partilhada com seus semelhantes.

Ou seja, ela trabalha com o universo de significados, motivos, aspirações, crenças, valores e atitudes na qual se constitui o ser humano, num espaço mais profundo de relações, não podendo 
assim reduzi-lo a quantificar e classificar como na abordagem quantitativa.

Nossa pesquisa foi do tipo exploratória, explicativa e descritiva. Exploratória visto que foi realizada sobre movimentos sociais de cunho feminista com o propósito de desvelar e compreender os vários aspectos desse tema em diferentes lutas sociais. Segundo a contribuição de Gil (2002, p. 41):

Pode-se dizer que estas pesquisas têm como objetivo principal o aprimoramento de idéais ou a descobertas de instituições. Seu planejamento é, portanto, bastante flexível, de modo que possibilite a consideração dos mais variados aspectos relativos ao fato estudado.

Foi também explicativa, pois tem a preocupação central de identificar o processo de formação política da Marcha Mundial das Mulheres e os fatores que contribuem para a ocorrência de fenômenos que afetam de maneira positiva ou negativa, os processos de luta e resistência do mesmo. Segundo as contribuições de Gil (2002, p. 42):

Tem como preocupação central identificar os fatores que determinam ou que contribuem para a ocorrência dos fenômenos. Esse é o tipo de pesquisa que mais aprofunda o conhecimento da realidade, porque explica a razão, o porquê das coisas.

Considera-se descritiva, pois descrevemos as principais condições de opressão sexista em que as mulheres vivem no patriarcado. Nessa perspectiva, a pesquisa descritiva, segundo Gil (2002, p. 42):

Tem como objetivo primordial a descrição das características de determinada população ou fenômeno ou, então, o estabelecimento de relações entre variáveis. São inúmeros os estudos que podem ser classificados sob este título e uma de suas características mais significativas está na utilização de técnicas padronizadas de coleta de dados, tais como o questionário e a observação sistemática.

Delimitamos o nosso tipo de pesquisa a partir das contribuições de Gil e Lage, pois entendemos que uma pesquisa em movimentos sociais, precisa de inferências exploratórias, explicativas e descritivas. Visto que é nesta direção que pretendemos dar visibilidade à 
luta feminista e refletir sobre as formações políticas que perpassam por suas ações.

A nossa pesquisa foi respaldada a partir do método do caso alargado (SANTOS, 1983) que consiste, segundo este autor, em alargar a realidade através de um caso particular estudado e estender as conclusões desse estudo a casos mais amplos. Não se trata de mera generalização, mas sim de encontrar singularidades e elementos estruturais em comum que unam o caso conhecido aos não-conhecidos.

Desta forma, para estudarmos as formações políticas que perpassam o movimento feminista carecemos de um campo empírico específico, pois não conseguiríamos atingir a demanda dos vários grupos feministas com suas perspectivas singulares que travam várias batalhas pelo empoderamento. Segundo Boaventura de Sousa Santos (1983):

Em vez de reduzir os casos às variáveis que os normalizam e tornam mecanicamente semelhantes, procura analisar, com o máximo de detalhe descritivo, a complexidade do caso, com vista a captar o que há nele de diferente ou de único. A riqueza do caso não está no que nele é generalizável, mas na amplitude das incidências pela multiplicidade e profundidade das interações que os constituem. (SANTOS, 1983, p. 11-12)

De forma geral a curiosidade da pesquisa é voltada para um movimento, que é amplo. Sendo assim, precisamos de um campo empírico, um espaço concreto e acessível. A partir do estudo desse caso é possível, através do método do caso alargado, estender a outros campos contemplando, assim, o movimento feminista como um todo, haja visto que sua pauta de reivindicações possui a mesma natureza e atua de forma parecida num espaço geográfico enorme que é a área do Brasil, através dos municípios.

A nossa pesquisa foi realizada no movimento feminista denominado "Marcha Mundial das Mulheres". Neste sentido, a principal característica que nos levou a escolher esta experiência foi a forma com que a Marcha Mundial das Mulheres busca realizar debates e formações que falam acerca da luta incansável das mulheres para a resistência da reprodução dessa sociedade machista e patriarcal.

A pesquisa de campo foi realizada na Marcha Mundial das Mulheres, que não possui uma sede fixa, utilizando de outros espaços como o MMTR -NE (Movimento da Mulher Trabalhadora 
Rural do Nordeste), na Casa do Pífano, Estação Ferroviária, Sinpro, entre outros espaços na cidade de Caruaru, com o propósito de levantar dados empíricos de modo a confrontar teoria e prática. Desta maneira, fomos a palestras, reuniões, formações, atos, mobilizações, vigílias.

As fontes de informação utilizadas para a coleta de dados foram realizadas com as integrantes da Marcha Mundial das Mulheres, visto que este é um movimento coletivo, onde não se tem presidenta, coordenadoras ou funcionárias. Foram escolhidas três mulheres militantes da Marcha Mundial das Mulheres - núcleo Agreste, optamos por manter a identidade das participantes em sigilo, utilizaremos os nomes de algumas mulheres feministas que marcaram a história desse movimento, sendo elas:

- Uma mulher que está presente desde a formação do núcleo Agreste, na qual evocaremos na pesquisa de Simone de Beauvoir ${ }^{2}$

- Uma mulher que está há mais de um ano no coletivo, que evocamos de Clarice Lispector ${ }^{3}$

- Uma mulher recém-chegada ao coletivo, que a evocamos de Malala ${ }^{4}$

Como instrumento de coleta de dados, fizemos o uso de entrevistas não estruturadas (SANTOS, 1983, p. 12) com as integrantes da Marcha Mundial das Mulheres da nossa pesquisa. Justificamos também a entrevista como metodologia da pesquisa qualitativa. (DESLAURIERS, 2008, p. 142) Para não impor de alguma maneira os sujeitos e não as obrigar a dar respostas ensaiadas definimos pela entrevista informal que tem o objetivo "menos estruturado possível e só se distingue da simples conversação porque tem como objetivo básico a coleta de dados". (GIL, 2008, p. 111)

\section{O contexto da formação política do movimento feminista marcha mundial das mulheres - núcleo agreste}

Utilizamos nesta investigação o método do Caso Alargado, desenvolvido por Boaventura de Sousa Santos (1983). A partir do estudo desse caso é possível, através do método do caso alargado, estender a outros campos contemplando, assim, a urgência da formação política das mulheres.
(2) Escritora, intelectual, filósofa existencialista, ativista política, feminista e teórica social francesa. (3) Autora de romances, contos, ensaios, sendo considerada uma das maiores escritoras brasileiras do século $X X$.

(4) Uma ativista paquistanesa. É conhecida principalmente pela defesa dos direitos humanos das mulheres e do acesso à educação. 
A criação da Marcha Mundial das Mulheres teve sua inspiração, a partir de uma ação local, de feministas da Federação de Mulheres do Quebec, Canadá. Em maio de 1995, onde ocorreu uma marcha na qual as mulheres pediam simbolicamente "Pão e Rosas", como forma de pressionar o governo, para melhorar a situação econômica das mulheres. Essas mulheres desejavam compartilhar suas experiências com outras mulheres de todo o mundo, buscaram contatos com organizações de mulheres em vários lugares.

A ideia de criar uma rede global de mulheres em torno de uma campanha amadureceu e desenvolveu durante a preparação do primeiro encontro da MMM realizado em Montreal, Quebec. Naquele encontro, participaram 145 mulheres de 65 países e territórios, por meio do qual elaboraram uma plataforma com 17 reinvindicações mundiais da Marcha, como temas principais trouxeram a eliminação da pobreza no mundo e o fim da violência contra a mulher. Também foi firmado o compromisso das participantes com a organização de uma marcha mundial das mulheres em 2000, ano do milênio, que aconteceria em 8 de março e terminaria em 17 de outubro no Dia Internacional pela Erradicação da Pobreza. A partir desse encontro, tiveram início concreto de mobilizações para as ações que viriam acontecer internacionalmente.

A principal característica e muito marcante da MMM é a batucada feminista, que tem como instrumentos musicais materiais reciclados como latas e tambores de plástico. A batucada é um espaço irreverente, no qual as mulheres podem criar e recriar. Trata-se de um espaço em que tocam os instrumentos construindo novos ritmos e músicas com palavras de ordem a partir do cotidiano e da luta de cada mulher. Tocar é uma forma de ação política de levar o feminismo para os olhares e ouvidos da rua expressando nossas lutas e ocupando o espaço público. Entre os princípios da MMM estão a organização das mulheres urbanas e rurais a partir da base e as alianças com movimentos sociais. Elas lutam em defesa de que as mulheres são sujeitas ativas na luta pela transformação de suas vidas e que ela está vinculada à necessidade de superar o sistema capitalista, patriarcal, racista, LGBTfóbico e destruidor do meio ambiente.

O caminho percorrido pela Marcha até chegar em Recife e se tornar o Núcleo Metropolitano, foi muito parecido com a chegada da MMM no Brasil, pois teve os movimentos sindicais como aporte para o início dos diálogos até estabelecer um grupo de mulheres. 
Atualmente, no estado de Pernambuco, temos quatro núcleos: Metropolitana, Agreste, Petrolina e Soledad Barrett.

A Marcha chegou ao núcleo Agreste em 2014, a partir das inquietações de Iasmim Vieira e Gaby Monteiro que já tinham experiências no Movimento das Mulheres Trabalhadoras Rurais do Nordeste (MMTR). Nesse meio tempo, elas ainda estavam na universidade e Iasmim fez a proposta na qual tiveram início os diálogos com Ranúzia e Gaby. A proposta seria fazer um coletivo feminista e então entraram em contato com as mulheres da Marcha Mundial da Mulheres - Metropolitana, que representavam a MMM núcleo Pernambuco; com muitos diálogos as militantes metropolitanas vieram a Caruaru para formações e em abril de 2014 aconteceu a primeira reunião convidando as mulheres para compor a MMM no núcleo Agreste e assim tem início uma revolução feminista no agreste de Pernambuco.

Para as militantes da marcha, é importante que nós mulheres compreendamos sobre o nosso papel, o significado do feminismo o que perpassa sobre os movimentos feministas e sua atuação. O grupo promove palestras, formações, atos, reuniões, manifestações com as mulheres em Caruaru com encontros alternados no domingo e na quinta-feira, sobre o empoderamento feminino e temas atuais como os casos de feminicídio, estupro, violência, entre outros.

Nesse tempo de somar lutas e trazendo a importância que o movimento feminista teve no processo de redemocratização do Brasil, perguntei a algumas companheiras da marcha quando foi sua primeira experiência com feminismo. Percebemos, então, o quanto a universidade é importante na construção desses diálogos, ofertando disciplinas que tragam o conhecimento, a luta e os princípios dos movimentos sociais, para que possamos nos encontrar como sujeitos participativos de uma bandeira de luta. Como nos mostram as militantes da marcha:

Com o movimento feminista veio através da universidade. Eu já brigava por alguns direitos, mas só conhecia do movimento o que as pessoas criticam. Ai quando cheguei na UFPE foi que tive conhecimento do que realmente e o feminismo e como o movimento funciona, ai me encontrei nele. (Feminista Malala, 26 anos)

A minha primeira experiência com feminismo se deu na universidade, já havia escutado muitas falas sobre o tema, mas de forma esclarecedora se deu a partir de uma disciplina ofertada 
pelo curso, que me deixou cheia de inquietações e me fez buscar mais informações, conhecimentos e organizações que debatessem o tema para que eu pudesse agregar e fazer parte desse movimento. (Feminista Clarice Lispector, 29 anos)

Refletimos como hoje ainda têm muitas mulheres que não compreendem o que é o feminismo, o que é pautado, suas reivindicações, suas conquistas, suas lutas, seus retrocessos, a partir do momento que você conhece, passa pelos processos de diálogos começam a se apropriar desse empoderamento, de dizer que não vamos nos deixar ser oprimidas pelo machismo, que temos direitos, que não nos calamos diante do que a sociedade nos impõe, que se mexer com uma mexeu com todas.

\section{Formação política}

Atualmente, vemos uma grande militância por parte dos movimentos sociais, com grande dificuldade, mas tendo também muitas conquistas. Vivemos um cenário no qual, as pautas de reivindicações têm uma grande demanda política, pois foi observado que se fazia necessário uma formação interna dos membros do movimento para tomada de consciência, pois esses membros é que trazem o povo para junto da sua ideologia, com isso eles se apropriavam da teoria para encontrar possíveis soluções em prol de melhorias sociais para a população. A partir dessa perspectiva em que se fazem necessárias as formações para compreensão da luta em que se encontra engajada, a feminista Clarice Lispector participante da pesquisa, traz a importância dessas formações e alguns assuntos que são dialogados nesses espaços de formação:

\footnotetext{
Vejo a formação política da Marcha, como uma apropriação de conhecimento das vivências de outras compas e do científico, que nos ajudam a pautar nossas ações coletivas com propostas de reinvindicações mais fortalecidas e reunindo mais companheiras para participar da nossa luta. Os temas que mais usamos são a violência contra a mulher, a emergência de mais mulheres no meio político, a luta pela democracia, a legalização do aborto, a atual conjuntura do país, a idealização de eventos como o 8 de março, etc. (Feminista Clarice Lispector, 29 anos)
}

Compreendemos que a Marcha é um espaço de diálogo, no qual as companheiras trocam experiências vividas, que planejam 
as formações pensando nas mais variadas mulheres que irão participar, utilizam de recursos artísticos, como é o caso da batucada e da mística, que ao decidirem de forma coletiva o tema pautado para a formação, utilizam de textos teóricos para fortalecer e internalizar nas mulheres a importância, o objetivo, os destaques, as relevâncias que determinado tema exige para nossa formação como mulher, nesta sociedade patriarcal, misógina e sexista.

\section{Patriarcado}

Ao analisarmos o sistema patriarcal e as suas práticas sexistas percebemos que estas formam o pilar da nossa sociedade e que vêm cada vez mais sendo impregnadas em nossas mentes, embora os movimentos feministas lutem diariamente contra essas opressões que nos sãos impostas, ainda precisamos resistir, combater e nos fortalecer para seguirmos nessa caminhada que ainda está muito longe de acabar. Podemos perceber na fala da companheira Malala que

Embora muito se venha conquistando na luta feminista, o sistema patriarcal é pilar da nossa sociedade, de forma que muitas conquistas ainda nos faltam, a renumeração igualitária de salários, muitas mulheres ainda vivem julgadas, dominadas e sem apoio de serviços especializados, a mercê da cultura do estupro, da violência contra a mulher e culpabilização da vítima, são algumas das lutas que ainda precisamos combater. (Feminista Malala, 26 anos)

Ainda conversando com as militantes sobre sua compreensão de opressões sexistas, e de exemplos que estas poderiam dar, no dia a dia, dessas formas de violência que as mulheres são condicionadas, as feministas trouxeram que:

[...] a sociedade nos condiciona por sermos mulheres, que já é uma opressão sexista, o sexismo representam ideias que privilegiam um grupo ou uma orientação sexual isso é colocar a mulher em forma de violência [...] opressões sexistas, são violências, violências para a nossa forma de ser, de se comportar, de querer, de fazer de agir em consequência de pensar, pois nós precisaremos controlar até os nossos pensamentos, até os nossos desejos. (Feminista Simone de Beauvoir, 29 anos) 
[...]temos opressões mais diretas, como o ódio entre as mulheres, que é uma armadilha do patriarcado para não unirmos forças, desde crianças somos ensinadas a sermos rivais. Além das opressões de comportamento, como nos vestir, por onde andar, como agir, etc. (Feminista Clarice Lispector, 29 anos)

As narrativas das feministas nos mostram o quanto é urgente as formações e diálogos acerca desse sistema patriarcal, que nos oprime cotidianamente e nos induz a rivalidade entre mulheres, que nos violentam por sermos subversivas e não seguirmos os padrões estabelecidos. A nossa luta é todo dia, pois a quebra dos estereótipos que nos inferiorizam socialmente não é fácil, as opressões sexistas nos bombardeiam em cada momento que transgredimos o que é moldado pelo patriarcado, essa afronta desestabiliza esse sistema misógino e auxilia na construção de uma sociedade igualitária.

\section{Concluindo}

Nosso estudo demonstrou que existe uma grande urgência de se pautar a formação política dentro dos movimentos feministas e coletivos para denunciar o caráter hegemônico do patriarcado. Mesmo com a opressão na vida das mulheres a Marcha Mundial das Mulheres - Núcleo Agreste, combate ao patriarcado de forma política e pedagógica, desestabilizando o ideário sexista imposto por esse regime.

E para desestabilizar esse ideário sexista a MMM trabalha na perspectiva de um feminismo na luta de classes e interseccional com outros movimentos sociais -Movimento LGBT, Movimento de mulheres Negras, Movimento de Mulheres Campesinas/Rurais, MST, Levante Popular, Frente Brasil Popular, Projetos e grupos de pesquisas de Universidades públicas e privadas, etc. -, promovendo ações de formação política e práticas não sexistas. E é dentro dessas esperanças de lutas sociais, que a prática política e educativa feminista se fazem tão importantes na nossa contemporaneidade, desestabilizando as classificações sociais e quebrando com os estereótipos e hierarquias de gênero.

Através do Método do Caso Alargado de Boaventura de Sousa Santos (1983), reafirmamos as urgências de se trabalhar cotidianamente a desestabilização do patriarcado, pautando em uma formação política de prática não sexista. Através de uma análise metodologicamente aprofundada. 
As reinvindicações no campo da formação política vivenciadas pela MMM são de caráter de urgência, pois traçar uma linha horizontal, não linear, baseada na valorização e no respeito da luta feminista, não deve ser encarada como um privilégio ou anarquia, mas sim o combate ao patriarcado e suas ramificações sexistas, pois seguiremos em marcha até que todas sejamos livres.

\title{
El proceso de formación política de la Marcha Mundial de las Mujeres - Núcleo Agreste de Pernambuco
}

\begin{abstract}
Resumen: Este artículo es un estudio sobre la formación política desarrollada en la Marcha Mundial de las Mujeres - Núcleo Agreste. Nuestro objetivo general es comprender cómo se desarrolla el proceso de formación política de la Marcha Mundial de las Mujeres frente a una sociedad patriarcal, junto con los objetivos específicos: identificar el proceso de formación política de la Marcha Mundial de las Mujeres; caracterizan el Movimiento de la Marcha Mundial de las Mujeres y describen las principales condiciones de opresión sexista que viven las mujeres en el patriarcalismo. Este trabajo se justifica por el surgimiento de una práctica feminista dentro de los movimientos sociales, como es el caso de la Marcha Mundial de las Mujeres - Núcleo Agreste. Nuestro problema es saber ¿cómo se desarrolla el proceso de formación política de la Marcha Mundial de las Mujeres frente a una sociedad patriarcal? En nuestra metodología adoptamos una investigación cualitativa / exploratoria / explicativa y descriptiva, sustentada en el estudio del Caso Extendido para el análisis y sistematización de datos, también utilizamos la Bases teóricas sustentadas en epistemologías feministas y teorías de género para ubicar nuestro trabajo en un contexto actual. Nuestras conclusiones estuvieron en la línea horizontal y no lineal de construir conocimiento sobre los enfrentamientos que surgen del patriarcado y el sexismo, construyendo una epistemología feminista de la práctica no sexista.
\end{abstract}

Palabras clave: Feminismo. Formación política. Género. Patriarcado.

\section{The process of political formation of the World March of Women - Pernambuco Agreste Center}

\begin{abstract}
This article is a study about the political formation developed in the World March of Women - Agreste Center. Our general objective is to understand how the process of political formation of the World March of Women in the face of a patriarchal society, together with the specific objectives: to identify the process of political formation of the World March of Women; characterize the Women's World March Movement and describe the main conditions of sexist oppression which women live in patriarchalism. This work is justified by the emergence of a feminist practice within social movements, as is the case of the World March of Women - Agreste Center. Our question is to know how the process of political formation of the World March of Women occurs in front of a patriarchal society? In our methodology we adopted a qualitative / exploratory / explanatory and descriptive research, supported by the study of the Extended Case for data analysis and systematization. Theoretical bases supported by feminist epistemologies and
\end{abstract}


gender theories to situate our work within a current context. Our conclusions were in the horizontal and nonlinear line of building knowledge about the confrontations arising from patriarchy and sexism, building a feminist epistemology of non-sexist practice.

Keywords: Feminism. Political formation. Genre. Patriarchy.

\section{Referências}

GIL, A. C. Como elaborar projetos de pesquisa. 4. ed. São Paulo: Atlas, 2002 .

GIL, A. C. Métodos e técnicas de pesquisa social. São Paulo: Atlas, 2008.

HOLLANDA, Heloísa Buarque de. Explosão feminista. São Paulo: Companhia das Letras, 2018.

LAGE, A. C. Educação e movimentos sociais: caminhos para uma pedagogia de luta. Recife: EdUFPE, 2013.

LAGE, A. C. Entre hegemonias e subalternidades, discursos e militâncias que apontam para uma ciência pós-colonial: é possível uma ciência mestiça? Revista do Observatório dos Movimentos Sociais Saberes, Caruaru, Ano 1, n. 1, p. 195-213, jul./ago./out., 2008.

MACEDO, A. G. Pós-feminismo. Revista Estudos Feministas, Florianópolis, v. 14, n. 3, p. 813-817, set./dez. 2006.

MARCHA MUNDIAL DAS MULHERES. Uma década de lucha internacional feminista. São Paulo: Maxprint, 2008.

MILITÃO, M. S. R. Formação política e movimentos sociais: uma perspectiva Gramsciana. Revista Educação e Filosofia, Uberlândia, v. 28, n. 56, p. 617-641, jul./dez. 2014.

MINAYO, M. C. S. (org.). Pesquisa social: teoria, método e criatividade. 27. ed. Petrópolis: Vozes, 2008.

MORGANTE, M. M.; NADER, M. B. O patriarcado nos estudos feministas: um debate teórico. In: ENCONTRO REGIONAL DE HISTÓRIA DA ANPUH-Rio: Saberes e práticas e científicas. 16., 2014, Rio de Janeiro. Anais. Rio de Janeiro: ANPUH, 2014. p. 1-10. Disponível em: http://www.encontro2014.rj.anpuh.org/resources/ anais/28/1399953465_ARQUIVO_textoANPUH.pdf.

PERELLA, C. dos S. S'A. Formação e participação políticas de Conselheiros de escola: o caso do município de Suzano-SP (2005-2009). 2012. Tese (Doutorado em Educação) - Faculdade de Educação, Universidade de São Paulo, São Paulo, 2012.

PINTO, C. R. J. Uma história do feminismo no Brasil. São Paulo: Fundação Perseu Abramo, 2003. 
SAFFIOTI, H. I. B. Gênero, patriarcado, violência. São Paulo: Editora Fundação Perseu Abramo, 2004.

SANTOS, B. de S. Os conflitos urbanos no Recife: o caso do "Skylab". Revista Crítica de Ciências Sociais, Coimbra, n. 11, p. 9-59, maio 1983.

SMIGAY, K. E. Sexismo, homofobia e outras expressões correlatadas de violência desafios para a psicologia política. Psicologia em Revista, Belo Horizonte, 2002.

TELES, M. A. de A. Breve história do feminismo no Brasil. São Paulo: Brasiliense, 1993. Disponível em: www.tse.jus.br/eleitot/glossário/ termos/voto-da-mulher. Acesso em: 2 abr. 2017. 